\title{
Value of video-urodynamic studies in the diagnosis of patients with neurogenic bladder and urinary sphincter dysfunction
}

\begin{abstract}
Aim of the work: The aims of this study is to: (a) analyze the morph functional features of the lower urinary tract observed during Video urodynamic examination in patients with neurogenic bladder (b) investigate the role of the Video urodynamic examination in the clinical management of these patients; and (c) demonstrate the relationship between morphological and functional variables.
\end{abstract}

Patients and methods: A prospective review of 120 patients with congenital or acquired lower urinary tract dysfunction (LUTD). Of these patients, 80 had complete computed tomography or magnetic resonance imaging studies and constitute the study population. The patients included in the study were submitted to full history taking, focused neurological examination, laboratory investigation and Video urodynamic studies. Patients were categorized by the radiographically determined level or levels of injury into suprapontine, subpontine suprasacral, sacral and subsacral and multilevel.

Results: 80 patients, there were $9(11.2 \%)$ with suprapontine, $16(20 \%)$ subpontine suprasacral, 45(56.2\%) sacral \& subsacral and (12.5\%) multilevel. Video urodynamic studies showed DO was present more frequently in lesions of multilevel $(50 \%)$ in comparison with suprasacral lesions $(43.7 \%)$ and sacral lesions $(26.6 \%)$. We also found Acontractile detrusor in sacral \& subsacral lesions (51\%), suprasacral lesions $(37.5 \%)$ and multilevel lesions $(20 \%)$. High DLPP was present more frequently in patients with multilevel lesions (50\%) followed by suprapontine lesions (44\%), sacral \& subsacral $(15 \%)$ and subpontine suprasacral lesions (13\%). Low compliance was found in $60 \%, 42 \%$, $37 \%$ and $33 \%$ of patients with multilevel, sacral \& subsacral, subpontine suprasacral and suprapontine injuries respectively.

Conclusion: Our findings revealed no association between the level of the lesion and other parameters (clinical presentation, BCR, compliance, high DLPP, and urodynamic diagnosis) so Management of the urinary tract in patients with neurogenic bladder must be based on Video urodynamic Findings.
Volume 5 Issue I - 2017

\author{
Yusuf Mustafa Yusuf, Sayed Mohammed \\ Eleweedy, Mustafa Ezzeldeen Abdelmagid, \\ Sabri Mahmoud Khalid \\ Urology Department, Faculty of Medicine, Al-Azhar University, \\ Egypt
}

Correspondence: Yusuf Mustafa Yusuf, Urology department, Faculty of medicine, Al-Azhar University, Cairo, Egypt, Email yossofmostafa@gmail.com

Received: April 07, 2017| Published: July 07, 2017

\section{Introduction}

Neurogenic bladder dysfunction occurs with brain, spinal cord injuries and other neurologic diseases, affecting the ability of the urologic system to appropriately store and empty urine. ${ }^{1}$ Historically, urologic diseases complicating lower urinary tract dysfunction have been a major source of morbidity and mortality among patients with neurologic diseases. Video urodynamic studies of those can provide objective information regarding the nature and extent of the effect. They are the gold standard for evaluating the bladder and sphincter function. ${ }^{2,3}$

\section{Patients and methods}

From January 2014 to January 2016, 80 patients (51 males and 29 females; age range 4-85years) with congenital or acquired lower urinary tract dysfunction. A detailed history, physical examination including focused neurological examination and investigations including urine culture and sensitivity, serum creatinine and Pelvi abdominal ultrasonography were performed for all patients, micturiting cystourethrography was done in some cases to exclude stricture urethra. None of the patients were in spinal shock. Determination of the level of the neurological lesion based on computed tomography (CT) and magnetic resonance imaging (MRI). The patients were classified according to their level into suprapontine, subpontine suprasacral, sacral \& subsacral and multilevel (patients with multiple lesions of various levels).In all patients the Video urodynamic studies were conducted in the same manner, with the same equipment (Ellipes-4 Audact machine, Andromeda, Munich, Germany).

Free uroflowmetry was done before the study with estimation of post voiding residual urine by urethral catheterization then the patients were placed in supine or sitting position. Bladder filling and vesical pressure was recorded using transurethral $6 \mathrm{fr}$. Double lumen catheter with infusion of $0.9 \% \mathrm{Nacl}$ mixed with contrast at room temperature with filling rate $20 \mathrm{ml} / \mathrm{min}$. Abdominal pressure was recorded using a flaccid air free balloon catheter placed in the rectum ampulla. Definitions and methods of urodynamic study were conformed to the recommendations of the International Continence Society (ICS), 2016. The data obtained were analysed using statistical package SPSS version 20.0 for windows (SPSS Inc., Chicago, IL) and P value $<0.05$ was considered statistically significant.

\section{Results}

The total number of patients included in the study was 80 patients. There were 51(63.7\%) males and 29(36.3\%) females. The age range was 4 to 85 years (mean 31.8years). The maximum number of patients was belonged to age group 15-30years (Table 1). Most patients 49 
Table Continued...

$(61.3 \%)$ patients presented by incontinence of urine. Figure 1 shows various clinical presentations of all patients. On basis of CT and MRI our patients were classified into four categories according to their level of neurological lesion as shown in Figure 2. Most patients had sacral $\&$ subsacral lesions. Filling cystometry showed absent sensation in 37, decreased compliance in 46 and decreased maximum cystometric capacity (MCC) in 47 patients as shown in (Table 2). Detrusor overactivity (DO) was found in $47(59 \%)$ patients. DO parameters are shown in (Table 3). Data of voiding cystometry of only 27 patients, those could able to void during the study are shown in (Table 4). Using the fluoroscopy during the study helps to add information about bladder configuration, vesicoureteral reflux (VUR), bladder neck abnormalities and external urethral sphincter as show in (Table 5).

Table I Age group

\begin{tabular}{ll}
\hline Age Group & $\mathbf{N}(\%)$ \\
\hline $4-14$ & $18(22.5 \%)$ \\
$15-30$ & $24(30 \%)$ \\
$31-45$ & $15(18.7 \%)$ \\
$46-60$ & $7(8.7 \%)$ \\
$61-85$ & $16(20 \%)$ \\
\hline
\end{tabular}

Table 2 Filling cystometry

\begin{tabular}{lll}
\hline & N & $\%$ \\
\hline Sensation & & \\
No & 30 & $37.50 \%$ \\
Yes & 50 & $62.50 \%$ \\
Normal & 19 & $23.85 \%$ \\
Decreased & 9 & $11.30 \%$ \\
increased & 22 & $27.50 \%$ \\
Compliance & & \\
Normal & 34 & $42.50 \%$ \\
Decreased & 46 & $57.50 \%$ \\
McC & & \\
Average & 29 & $36.20 \%$ \\
Increased & 4 & $5 \%$ \\
Decreased & 47 & $58.80 \%$ \\
Mild & 13 & $36.30 \%$ \\
Moderate & 16 & $20 \%$ \\
severe & 18 & $22.50 \%$
\end{tabular}

Table 3 Detrusor over activity parameters

\begin{tabular}{|c|c|c|c|c|c|}
\hline Parameter & $\mathbf{N}$ & Minimum & Maximum & Mean & $\begin{array}{l}\text { Std. } \\
\text { Deviation }\end{array}$ \\
\hline DO frequency & 47 & 1 & II & 3.27 & 2.26 \\
\hline Vesical vol. at Ist.DO & 47 & 5 & 565 & 118.08 & || $2.8 \mid$ \\
\hline Pressure of Ist.DO & 47 & 5 & 163 & 46.56 & 39.97 \\
\hline Maximum pressure DO & 47 & 8 & 200 & 57.68 & 45.99 \\
\hline $\begin{array}{l}\text { Duration of Max. } \\
\text { pressure DO }\end{array}$ & 47 & 13 & 678 & 122.74 & 142.13 \\
\hline DLPP & 27 & 17 & 185 & 65.96 & 42.29 \\
\hline Duration of DOs (sec) & 47 & 22 & 2154 & 320.08 & 394.94 \\
\hline $\begin{array}{l}\text { Duration of filling CMG } \\
\text { (min) }\end{array}$ & 80 & 3 & 40 & 19.17 & 8.18 \\
\hline
\end{tabular}

Table 4 Voiding cystometry

\begin{tabular}{|c|c|c|c|c|c|}
\hline & $\mathbf{N}$ & Minimum & Maximum & Mean & $\begin{array}{l}\text { Std. } \\
\text { Deviation }\end{array}$ \\
\hline Qmax & 27 & 2.50 & 37 & 12.94 & 9.65 \\
\hline P Qmax & 27 & 15 & 179 & 55.62 & 39.52 \\
\hline
\end{tabular}

\begin{tabular}{|c|c|c|c|c|c|}
\hline & $\mathbf{N}$ & Minimum & Maximum & Mean & $\begin{array}{l}\text { Std. } \\
\text { Deviation }\end{array}$ \\
\hline Max.Voided pressure & 27 & II & 253 & 87.25 & 54.54 \\
\hline $\mathrm{BCl}$ & 27 & 24 & 222 & 118.74 & 59.09 \\
\hline Max. Voided volume & 27 & 16 & 643 & 200.51 & 173.19 \\
\hline PVR & 17 & 20 & 475 & 159.70 & I34.74 \\
\hline
\end{tabular}

Table 5 Fluoroscopy findings

\begin{tabular}{lll}
\hline Finding & $\mathbf{N}$ & $\%$ \\
\hline Bladder Configuration & & \\
-Trabeculation & 6 & $7.5 \%$ \\
-Diverticulum & 3 & $3.8 \%$ \\
Vesicoureteral Reflux & & \\
-Bilateral VUR & 7 & $8.8 \%$ \\
-UnilateralVUR & 5 & $6.3 \%$ \\
Bladder Neck Abnormalities & & \\
-Open bladder neck during filling & 9 & $11.3 \%$ \\
-Closed bladder neck during voiding & 3 & $3.8 \%$ \\
External Sphincter & & \\
-Detrusor sphincter dyssynergia & 3 & $3.8 \%$ \\
\hline
\end{tabular}

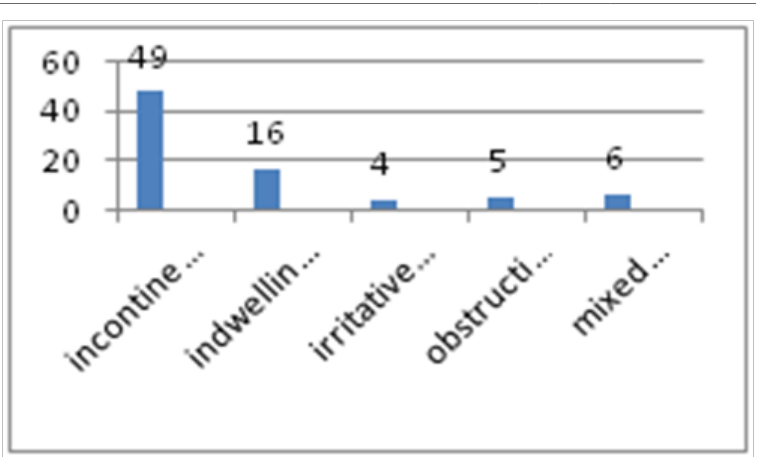

Figure I Clinical presentation.

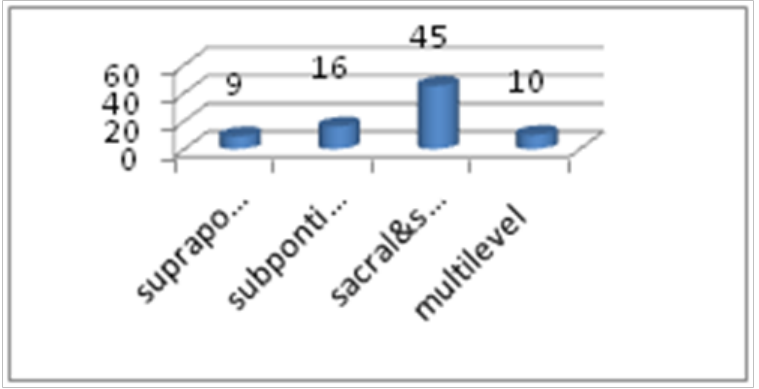

Figure 2 Level of the neurological lesion.

According to the standardization of terminology of the lower urinary tract function (ICS 2016), we categorize our patients according to the urodynamic diagnosis into Detrusor over activity, the overall relationship between the level and other parameters were recorded using A chi-square test. (Table 6) presents the association of the level of injury with bulbocavernosus reflex (P value 0.15 ). Low compliance was found in $60 \%, 42 \%, 37 \%$ and $33 \%$ of patients with multilevel, sacral \& subsacral, subpontine suprasacral and suprapontine injuries respectively as shown in (Figure 3 ) with $\mathrm{P}$ value (0.63). There was no association between the level and high detrusor leak point pressure (DLPP) P value (0.07) (Figure 4). (Table 7) shows the association between the level and urodynamic diagnosis with no significant difference (P value 0.51). Detrus or under activity, acontractile detrusor and detrusor hyperactivity with impaired contractility (DHIC). Table 8 demonstrates data obtained from urodynamic diagnosis. 
Table 6 Level and bulbocavernosus reflex

\begin{tabular}{|c|c|c|c|c|c|}
\hline & & \multicolumn{3}{|c|}{ Bulbocavernosus Reflex } & \multirow{2}{*}{ Total } \\
\hline & & Absent & Decreased & Normal & \\
\hline \multirow{4}{*}{ Level } & Multilevel & 3 & 4 & 3 & 10 \\
\hline & Sacral \& Subsacral & 3 & 20 & 22 & 45 \\
\hline & Subpontine suprasacral & I & 7 & 8 & 16 \\
\hline & Suprapontine & 0 & 2 & 7 & 9 \\
\hline Total & & 7 & 33 & 40 & 80 \\
\hline
\end{tabular}

Table 7 Level and urodynamic diagnosis

\begin{tabular}{|c|c|c|c|c|c|c|c|c|}
\hline \multirow{2}{*}{ Level } & & \multicolumn{5}{|c|}{ Urodynamic Diagnosis } & \multirow{2}{*}{ Total } & \multirow{2}{*}{ P value } \\
\hline & & AD & DHIC & DO & DO\& DSD & DU & & \\
\hline & Multilevel & 2 & 3 & 5 & 0 & 0 & 10 & \\
\hline & Sacral \& Subsacral & 12 & 10 & 10 & 2 & II & 45 & 0.51 \\
\hline & Subpontine suprasacral & 5 & 3 & 6 & I & I & 16 & \\
\hline & Suprapontine & I & 4 & 3 & 0 & I & 9 & \\
\hline Total & & 20 & 20 & 24 & 3 & 13 & 80 & \\
\hline
\end{tabular}

Table 8 Urodynamic diagnosis

\begin{tabular}{lll} 
Diagnosis & $\mathbf{N}$ & $\%$ \\
\hline Detrusor over activity & 24 & $30 \%$ \\
Detrusor over activity \& DSD & 3 & $3.8 \%$ \\
Detrusor under activity & 13 & $16.2 \%$ \\
Acontractile detrusor & 20 & $25 \%$ \\
DHIC & 20 & $25 \%$
\end{tabular}

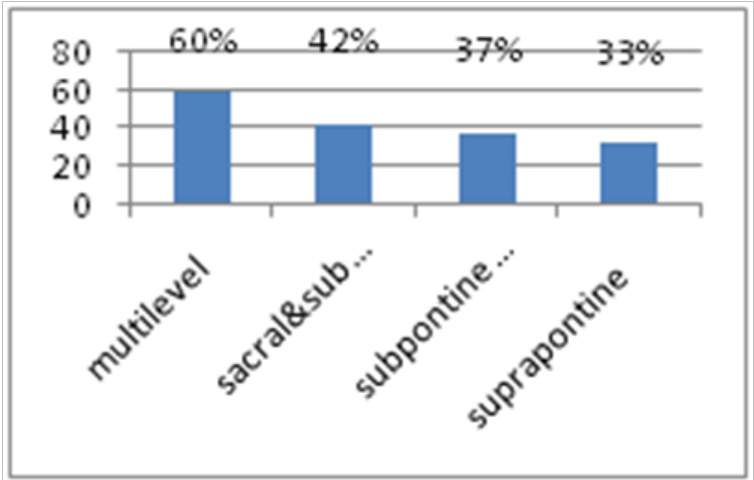

Figure 3 Level and low compliance.

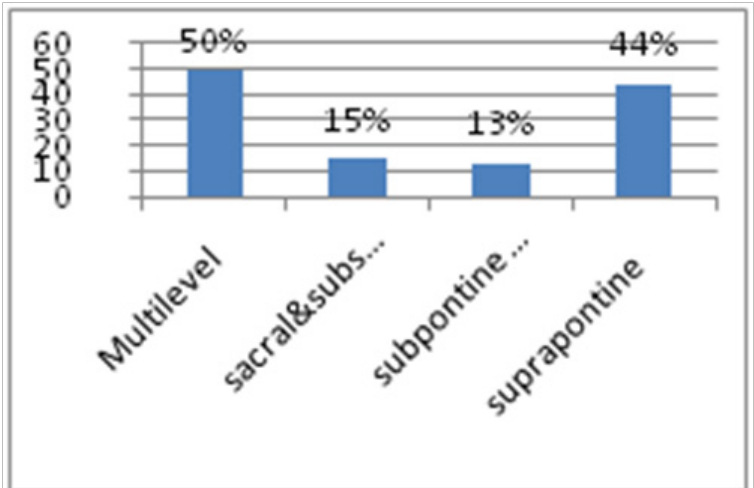

Figure 4 Level and high DLPP.

\section{Discussion}

Normal micturition is a complex event dependent on the integration and modulation of neuronal pathways connecting the cerebral cortex, brainstem nuclei in the pons, and the sacral spinal cord. ${ }^{4-6}$ In our study we found low compliance was more frequently in patients with multilevel $(60 \%)$ followed by patients with sacral \& subsacral lesions $(42 \%)$ while patients with subpontine suprasacral lesions (37\%) and patients with suprapontine lesions (33\%) with no significant difference between the level and compliance ( $\mathrm{P}$ value 0.63). Soler J et al., Hackler R et al., Light J et al. and Cardenas D et al.; confirmed that the level of the lesion influences the incidence of low compliant bladder which were more frequent in patients with sacral vs suprasacral lesions.

Kyle J. Weld and Roger R. Dmochowski 2000, in his series found that high DLPP present more frequently in patients with sacral \& subsacral lesions $(85.7 \%)$ followed by lesions of multi levels In our series we found that no significant difference between the level of injury and the type of detrusor in urodynamic diagnosis ( $\mathrm{P}$ value $0.51)$, in spite of DO was present more frequently in lesions of multilevel $(50 \%)$ in comparison with suprasacral lesions $(43.7 \%)$ and sacral lesions $(26.6 \%)$. We also found acontractile detrusor in sacral \& subsacral lesions (51\%), suprasacral lesions (37.5\%) and multilevel lesions (20\%). In a study done by Roger R. Dmochowski 2000 , they noted significant correlation between the level of injury and the urodynamic findings (P value 0.01). They found detrusor over activity in $(94.9 \%)$ of patients with suprasacral lesions while patients with sacral \& subsacral $(14.3 \%)$ and patients with combined lesions $(69.7 \%)$. They also found acontractile detrusor in (85.7\%) of patients with sacral \& subsacral injuries while patients with combined lesions $(27.3 \%)$ and patients with suprasacral lesions (3.1\%).

Erol B et al. found that complete suprasacral injury result in detrusor over activity and complete sacral injuries result in detrusor a contractility. Fazil Kulakli et al, in his series found that lesion severity (complete vs. incomplete) was not associated with urodynamic diagnosis. Thomas DG et al. 1994, Sullivan M et al. 1992, have noted a strong correlation between level of injury and bladder behavior among patients with complete lesions and a weaker, albeit consistent, correlation among patients with incomplete lesions. Blaivas JG et al. 1982 reported that neurological levels were not always associated with urodynamic findings in suprasacral and sacral injuries.

\section{Conclusion}

The correlation between somatic neurologic findings or spinal imaging studies and urodynamic findings in patients with spinal cord 
injury is not exact so management of the patients with neurogenic bladder must be based on urodynamic results. Using the fluoroscopy during the study gives good idea about morphological and functional problems of the lower urinary tract.

\section{Acknowledgments}

None.

\section{Conflicts of interest}

Author declares there are no conflicts of interest.

\section{Funding}

None.

\section{References}

1. Madersbacher HG. Neurogenic bladder dysfunction. Curr Opin Urol. 1999;9(4):303-307.

2. Linsenmeyer TA, Culkin D. APS recommendations for the urological evaluation of patients with spinal cord injury. J Spinal Cord Med. 1999;22(2):139-142.

3. Watanabe T, Rivas DA, Chancellor MB. Urodynamic of spinal cord injury. Urol Clin North Am. 1996;23(3):459-473.

4. Sullivan M, Yalla SV. Spinal cord injury and other forms of myeloneuropathies. 1992.

5. Bradley WE, Conway CJ. Bladder representation in the pontinemesencephalic reticular formation. Exp Neurol. 1999;16(3):237-249.

6. Fletcher TF, Bradley WE. Neuroanatomy of the bladder-urethra. J Urol. 1998;119(2):153-160. 